\title{
Exposure to diagnostic radiation and risk of breast cancer among carriers of BRCA1/2 mutations: retrospective cohort study (GENE-RAD-RISK)
}

\author{
(c) $\underset{0}{(1)(8)}$ OPEN ACCESS
}

Anouk Pijpe postdoctoral research fellow ${ }^{1}$, Nadine Andrieu senior researcher ${ }^{234}$, Douglas F Easton professor $^{5}$, Ausrele Kesminiene study coordinator ${ }^{6}$, Elisabeth Cardis professor ${ }^{7}$, Catherine Noguès oncogeneticist $^{8}$, Marion Gauthier-Villars oncogeneticist ${ }^{9}$, Christine Lasset oncogeneticist ${ }^{10}$, Jean-Pierre Fricker oncogeneticist ${ }^{11}$, Susan Peock study coordinator ${ }^{5}$, Debra Frost research assistant $^{5}$, D Gareth Evans professor ${ }^{12}$, Rosalind A Eeles clinical cancer geneticist ${ }^{13}$, Joan Paterson clinical geneticist ${ }^{14}$, Peggy Manders postdoctoral research fellow ${ }^{15}$, Christi $\mathrm{J}$ van Asperen clinical geneticist $^{16}$, Margreet G E M Ausems clinical geneticist ${ }^{17}$, Hanne Meijers-Heijboer clinical geneticist ${ }^{18}$, Isabelle Thierry-Chef researcher ${ }^{6}$, Michael Hauptmann statistician ${ }^{1}$, David Goldgar senior researcher $^{19}$, Matti A Rookus senior research fellow ${ }^{1}$, Flora E van Leeuwen professor ${ }^{1}$, on behalf of GENEPSO, EMBRACE, and HEBON

${ }^{1}$ Netherlands Cancer Institute, Department of Epidemiology and Biostatistics, Plesmanlaan 121, 1066 CX Amsterdam, Netherlands; ${ }^{2}$ Institut National de la Santé et de la Recherche Médicale, Unité U900, Paris 75248, France ; ${ }^{3}$ Institut Curie, Research Centre and Service of Biostatistics, Paris $75248 ;{ }^{4}$ Ecole des Mines de Paris, Paris Tech, Fontainebleau 77300, France $;{ }^{5}$ Centre for Cancer Genetic Epidemiology, Department of Public Health and Primary Care, University of Cambridge, Strangeways Research Laboratory, Cambridge CB1 8RN, UK; ${ }^{6}$ International Agency for Research on Cancer, Section of Environment and Radiation, 69372 Lyon 08, France; ${ }^{7}$ Centre for Research in Environmental Epidemiology (CREAL), IMIM (Hospital del Mar Research Institute), CIBER Epidemiologica y Salud Pública (CIBERESP), Doctor Aiguader, 88, 08003 Barcelona, Spain; ${ }^{8}$ Institut Curie, Hôpital René Huguenin, 92210 Saint-Cloud, Paris; Institut Curie, Service d’Oncogénétique, 75005 Paris; ${ }^{10}$ Centre Léon Bérard, 69008 Lyon; ${ }^{11}$ Centre Paul Strauss, 67065 Strasbourg, France; ${ }^{12}$ Department of Genetic Medicine, St Mary's Hospital, Manchester M13 9WL, UK; ${ }^{13}$ Oncogenetics Team, Institute of Cancer Research and Royal Marsden NHS Foundation Trust, Sutton, Surrey SM2 5PT, UK; ${ }^{14}$ Department of Clinical Genetics, East Anglian Regional Genetics Service, Addenbrookes Hospital, Cambridge CB2 0QQ; ${ }^{15}$ Department of Human Genetics, Radboud University Nijmegen Medical Centre, 6525 GA Nijmegen, Netherlands; ${ }^{16}$ Department of Clinical Genetics, Leiden University Medical Centre, 2333 ZA Leiden, Netherlands; ${ }^{17}$ Department of Medical Genetics, University Medical Centre Utrecht, 3584 CX Utrecht, Netherlands; ${ }^{18}$ Department of Clinical Genetics and Human Genetics, VU University Medical Centre, Amsterdam; ${ }^{19}$ Department of Dermatology, University of Utah School of Medicine, Salt Lake City, Utah 84132, USA

\author{
Abstract \\ Objective To estimate the risk of breast cancer associated with \\ diagnostic radiation in carriers of BRCA1/2 mutations. \\ Design Retrospective cohort study (GENE-RAD-RISK). \\ Setting Three nationwide studies (GENEPSO, EMBRACE, HEBON) in \\ France, United Kingdom, and the Netherlands, \\ Participants 1993 female carriers of BRCA1/2 mutations recruited in \\ 2006-09.
}

\begin{abstract}
Main outcome measure Risk of breast cancer estimated with a weighted Cox proportional hazards model with a time dependent individually estimated cumulative breast dose, based on nominal estimates of organ dose and frequency of self reported diagnostic procedures. To correct for potential survival bias, the analysis excluded carriers who were diagnosed more than five years before completion of the study questionnaire.
\end{abstract}

Results In carriers of BRCA1/2 mutations any exposure to diagnostic radiation before the age of 30 was associated with an increased risk of 
breast cancer (hazard ratio 1.90, 95\% confidence interval 1.20 to 3.00), with a dose-response pattern. The risks by quarter of estimated cumulative dose $<0.0020 \mathrm{~Gy}, \geq 0.0020-0.0065 \mathrm{~Gy}, \geq 0.0066-0.0173 \mathrm{~Gy}$, and $\geq 0.0174$ Gy were 1.63 (0.96 to 2.77 ), 1.78 (0.88 to 3.58), 1.75 (0.72 to 4.25$)$, and 3.84 (1.67 to 8.79 ), respectively. Analyses on the different types of diagnostic procedures showed a pattern of increasing risk with increasing number of radiographs before age 20 and before age 30 compared with no exposure. A history of mammography before age 30 was also associated with an increased risk of breast cancer (hazard ratio $1.43,0.85$ to 2.40 ). Sensitivity analysis showed that this finding was not caused by confounding by indication of family history.

Conclusion In this large European study among carriers of BRCA1/2 mutations, exposure to diagnostic radiation before age 30 was associated with an increased risk of breast cancer at dose levels considerably lower than those at which increases have been found in other cohorts exposed to radiation. The results of this study support the use of non-ionising radiation imaging techniques (such as magnetic resonance imaging) as the main tool for surveillance in young women with BRCA1/2 mutations.

\section{Introduction}

Exposure to ionising radiation is an established risk factor for breast cancer in the general population, with exposures in childhood and adolescence conferring a greater risk than exposure in adulthood. ${ }^{1}$ As BRCA1 and BRCA2 are involved in the repair of DNA double strand breaks, ${ }^{2-6}$ which can be caused by ionising radiation, it has been hypothesised that carriers of BRCA1/2 mutations might have increased radiosensitivity. Results of the few studies ${ }^{7-10}$ conducted so far on diagnostic radiation and risk of breast cancer among carriers have been inconsistent. Explanations for this inconsistency include differences in age at exposure and study limitations such as the investigation of a single type of diagnostic procedure (such as only chest radiography ${ }^{78}$ or only mammography ${ }^{9}{ }^{10}$ ), a retrospective design with potential recall and/or survival bias,${ }^{7-10}$ or sometimes relatively small numbers. ${ }^{8}{ }^{9}$ In some countries the screening protocol for BRCA1/2 mutation carriers now recommends the avoidance of mammographic screening before age 30 and advises the use of non-ionising radiation imaging techniques (such as magnetic resonance imaging (MRI)) as the main tool for surveillance at young ages.

We report on the BRCA1/2 mutation carrier study arm of the GENE-RAD-RISK project, a large European cohort study designed to examine whether variations in specific DNA repair genes increase the risk of breast cancer associated with radiation. Although the present study has a retrospective design, the association between diagnostic radiation and breast cancer risk in BRCA1/2 mutation carriers is unlikely to be investigated prospectively in the near future. This is because incident case numbers are not expected to increase rapidly because of the increasing uptake of prophylactic surgery among unaffected BRCA1/2 mutation carriers and the relatively short follow-up since DNA testing for BRCA mutations became available (1995), together with the fact that many newly identified carriers were tested because they (already) had breast cancer.

\section{Methods}

\section{Study population}

The present study included 1993 women who were tested in a clinical setting (that is, at a clinical genetic centre), identified as carrying a pathogenic BRCA1 or BRCA 2 mutation, and aged 18 or older. Women were recruited into the GENE-RAD-RISK cohort study in 2006-09 and were participants in three large ongoing national cohort studies of carriers in France
(GENEPSO; $\mathrm{n}=716(36 \%)$ ), the UK (EMBRACE ${ }^{11} ; \mathrm{n}=688$ $(35 \%)$ ), and the Netherlands $\left(\mathrm{HEBON}^{12} ; \mathrm{n}=589(30 \%)\right)$.

Each participant completed a standardised questionnaire (response rate $78 \%$; see supplementary table A). Diagnoses of breast cancer were recorded through linkage with national registries or medical records.

\section{Exposure to diagnostic radiation}

Participants reported their history of exposure to diagnostic radiation in a detailed questionnaire containing indication based questions on lifetime exposure to fluoroscopy, conventional radiography of the chest/shoulders, mammography, computed tomography of the chest/shoulders, and other diagnostic procedures that use ionising radiation (such as bone scans) involving the chest or shoulders. Each section of the questionnaire provided a detailed description of the procedure and its most common indications. For fluoroscopy, radiography, and mammography, we asked about ever/never exposure, age at first exposure, number of exposures before age 20 , and at ages 20-29 and 30-39, and age at last exposure. For each of the other exposure types, participants reported the indication, age at exposure, and number of exposures.

We estimated the cumulative breast dose as an approximation of breast dose in units of Gy. Nominal estimates of breast dose for fluoroscopy, radiography, mammography, and computed tomography were derived from a literature review of published studies and institutional reports assessing radiation dose delivered to the breast from radiological examinations and expert judgment by ITC, AK, FvL, and AP (table $1 \Downarrow$ ). When possible, we restricted the selected studies and reports to European studies performed on large samples, representative of patients and radiology services. The cumulative breast dose estimate was the sum of the age and calendar specific number of self reported diagnostic procedures multiplied by nominal estimates of breast dose.

\section{Statistical analysis}

We used a Cox proportional hazards model to calculate adjusted hazard ratios of breast cancer and $95 \%$ confidence intervals, with age (in years) as time scale and cumulative radiation exposure from diagnostic procedures as a time dependent variable lagged by five years to exclude procedures that could have been performed because of a diagnosis of breast cancer and exclusion of radiation dose that probably did not contribute to induction of breast cancer. All analyses were stratified for gene (BRCA1 and BRCA2), birth cohort $(<1955,1955-61$, 1962-68, >1968), and country (UK, France, and the Netherlands), and clustered on family. Standard Cox regression leads to biased estimates of the hazard ratio because the women in this study were selected from high risk families qualifying for genetic testing. The disease status might therefore have increased the likelihood of ascertainment leading to an oversampling of affected women. To correct for this potential bias (testing bias), we used the weighted regression approach described by Antoniou et al. ${ }^{13}$ With this procedure, individuals are weighted according to certain sampling probabilities such that the observed weighted incidence rate agrees with the true incidence rate in a similar but unselected cohort. The value of the weight depends on the age interval in which the person's follow-up ends - that is, weights were assigned for each mutation and age category based on incidence rates from a population based study. ${ }^{14}$ Case weights were consistently lower than 1, indicating that cases are oversampled in the study. By the weighted regression approach, hazard ratios are typically 
shifted away from the null value $(=1)$ at the cost of some power (wider confidence intervals).

We defined two types of analytical cohorts: the entire cohort and a subcohort. In the entire cohort analysis, follow-up started at birth and ended at the date of the first diagnosis of breast cancer $(\mathrm{n}=848)$, other cancers excluding basal cell carcinoma $(n=96)$, date of bilateral prophylactic mastectomy $(n=234)$, or completion of the questionnaire $(n=815)$, whichever occurred first. There were 78074 person years of observation. In all retrospective cohort studies that use questionnaire data, affected women who survived until questionnaire completion could fill out the questionnaire only because they have survived. If the exposure under investigation is associated with worse survival, cases without exposure would be more strongly represented, introducing bias to the null. Although little is known about the influence of exposure to ionising radiation, low or high dose, on overall survival and breast cancer specific survival in carriers, there are indications that breast cancer associated with radiation has a distinct, less favourable, gene expression profile. ${ }^{15}$ To correct for potential survival bias arising from the exclusion of exposed carriers who died from breast cancer long before questionnaire completion, we carried out our main analyses on relatively recent cases - that is, carriers who received diagnosis of a breast cancer or who were censored within the five years before completion of the questionnaire. Follow-up was counted only during this five year period and with a new set of period specific weights. This subcohort analysis contained a total of 1122 participants, 174 of whom had breast cancer. There were 4484 person years of observation. Although based on smaller numbers, we consider the results of the subcohort to be the most valid and have therefore presented these results in the main text. We have presented the results from the entire cohort in supplementary tables and briefly summarise them in the results section.

As exposure to diagnostic radiation was reported in decades of age, we assumed that exposures were equally distributed across each decade, taking into account ages at first and last exposure. This resulted in the following categorisation for cumulative number of exposures: $1=0.5-1.4 ; 2=1.5-2.4 ; 3-4=2.5-4.4 ;>4=4.5$ or more. The estimate of cumulative breast dose was categorised based on quarters of cumulative dose at age 40 .

We observed no violation of the proportional hazards assumption by any variable. Tests for trend of number of exposures were conducted by assigning to each individual the median of the number of exposures in each exposure category (rather than the individual's reported number of exposures) and including this as a continuous variable in an unweighted procedure specific model. Missing values in ever/never exposure $(<11 \%)$ and covariates $(<1 \%)$ were coded as an additional category. Among carriers with any exposure to diagnostic radiation, missing values for age at first exposure $(<15 \%$ for fluoroscopy and radiography and $<10 \%$ for mammography) and last exposure $(<5 \%)$ and number of exposures $(<21 \%$ for fluoroscopy and radiography and $<7 \%$ for mammography) were imputed by age period, with the mean age and number of exposures of women for whom complete data were available. Linear excess relative risks per Gy were estimated by unweighted conditional logistic regression with SAS code. ${ }^{16}$ We adjusted the risk estimates for the analyses of cumulative breast dose for parity and menopausal status. We adjusted analyses of radiography and mammography for age at menarche, parity, and menopausal status. Other potential confounding factors, including age at first full term pregnancy and breast feeding, did not change the log(hazard ratio) estimates by more than $10 \%$ and were omitted from final models. We examined effect modification by country, BRCA1 versus BRCA2, birth cohort, and attained age. Two sided $\mathrm{P}<0.05$ was considered significant. Analyses were performed with Stata/SE 11.0 (StataCorp).

\section{Results}

In the entire cohort, $43 \%(\mathrm{n}=848)$ of carriers had received a diagnosis of breast cancer (table $2 \Downarrow$; of these $89 \%(n=755)$ were confirmed by medical records or linkage with national registries. There was no difference between cases and unaffected carriers in age at diagnosis of breast cancer and age at censoring (mean 39.5 (SD 7.4) and 39.7 (SD 7.4) for cases and unaffected carriers respectively; $\mathrm{P}=0.601)$. Women with breast cancer, however, were older at questionnaire completion (49.7 (SD 8.6) v 42.1 (SD 10.5), $\mathrm{P}<0.001)$. In general, there were no differences in characteristics between the entire cohort and the subcohort, though the carriers in the subcohort were on average younger at questionnaire completion than those in the entire cohort (41.1 $(\mathrm{SD} 9.7) v 50.7$ (SD 8.8), $\mathrm{P}<0.001)$.

Radiography was the most common diagnostic procedure; $48 \%$ $(n=919)$ of carriers reported ever having had a radiograph while $33 \%(n=649)$ had ever had a mammogram (table $3 \Downarrow)$. The median numbers of procedures before age 40 were 2.5 for radiography and 2.4 for mammography. The mean age at first mammogram was 29.5 (SD 5.8). Only a small proportion $(<5 \%)$ of carriers were ever exposed occupationally, during pregnancy or during breast feeding, to computed tomography or other diagnostic radiation procedures (table 3 ). None of the carriers had received radiotherapy before the end of follow-up because cancers other than breast cancer were censored. The mean estimated cumulative breast dose from fluoroscopy, radiography, mammography, and computed tomography combined was 0.0140 Gy and ranged from 0.0005 to $0.6130 \mathrm{~Gy}$ (interquartile range 0.0020-0.0174 Gy).

Table 4 shows the results of the analyses on cumulative breast dose and risk of breast cancer $\Downarrow$. When compared with no exposure, any exposure before age 30 was associated with an increased risk (hazard ratio $1.90,95 \%$ confidence interval 1.20 to 3.00). We also observed a pattern of increasing risk with increasing dose; for a cumulative dose estimate of more than $0.0174 \mathrm{~Gy}$ we observed an almost fourfold increased risk of breast cancer $(3.84,1.67$ to 8.79$)$. A similar increased risk was observed for exposure before age 20 even after a lower dose of more than 0.0066 Gy $(3.16,1.19$ to 8.39$)$. There was no evidence of an increased risk of breast cancer associated with exposure at ages 30-39. The unweighted excess relative risks per $\mathrm{Gy}$ for exposures before ages 40 and 30 were $14.76(\mathrm{P}=0.138)$ and $29.81(\mathrm{P}=0.100)$.

In the analysis of specific diagnostic procedures we observed a trend of increasing risk of breast cancer with increasing number of radiographs before age $20(\mathrm{P}=0.041$ for trend) and a non-significantly increased risk of breast cancer after more than two fluoroscopies before age 20 (hazard ratio $2.01,95 \%$ confidence interval 0.71 to $5.71, \mathrm{P}=0.102$ for trend) compared with no exposure (table $5 \Downarrow$ ). Furthermore, there was a non-significantly increased risk of breast cancer after exposure to mammography before age $30(1.43,0.85$ to $2.40, \mathrm{P}=0.040$ for trend). We observed an almost twofold risk increase for exposure to more than four radiographs before age 30 (1.83, 0.84 to $4.00, \mathrm{P}=0.012$ for trend) and for more than four radiographs at ages $30-39(2.04,0.85$ to $4.90, \mathrm{P}=0.101$ for trend; data not shown), though this latter category included only six cases. We found no other associations between exposure at ages 30-39 and risk of breast cancer. 
The risk estimates presented in tables 4 and 5 were not materially affected by inclusion of the estimates for each age period (that is, $<20,20-29$, and 30-39 years) in the same model or by adjustment for occupational exposure. The results of the procedure specific analyses did not change when we included different exposure types in one model. The results did not differ by country (data not shown). Use of a two or 10 year time lag did not materially affect the results (data not shown).

A strong family history of breast cancer could be an indication for mammographic screening at a young age. We investigated this potential bias away from the null by a subgroup analysis of the cumulative breast dose in carriers who never had a mammogram before age 30 (table $6 \Downarrow$ ). This resulted in a similar association compared with the complete model (table 4).

We investigated whether there was a difference in the association between exposure to diagnostic radiation and risk of breast cancer for BRCA1 and BRCA2 carriers. Among BRCA1 carriers, any exposure before age 30 was associated with an increased risk (hazard ratio $2.83,95 \%$ confidence interval 1.59 to 5.04) and the following pattern of dose-response emerged: risks for cumulative dose estimates of $<0.0020 \mathrm{~Gy}$,

$\geq 0.0020-0.0065 \mathrm{~Gy}, \geq 0.0066-0.0173 \mathrm{~Gy}$, and $\geq 0.0174$ Gy were 2.46 (1.27 to 4.77 ), 2.45 (1.02 to 5.90), 2.72 (0.99 to 7.44), and 5.00 (1.96 to 12.74$)$, respectively. For BRCA2 carriers we did not observe an association in the subcohort, but this analysis was limited because of the small number of cases. The $\mathrm{P}$ value for interaction between gene and ever versus never exposure before age 30 was 0.631 . We also evaluated risk associated with exposure before the age of 30 by attained age below and above the median of 40 to examine the effect of time since exposure. We observed a non-significant higher risk for the younger attained age group compared with the older age group (1.87 (1.13 to 3.10$) v 1.64$ (1.00 to 2.68$)$, respectively). We observed no effect modification by birth cohort $(\mathrm{P}>0.05$ for interaction; data not shown).

In the entire cohort, a history of any exposure before age 30 was also associated with a significantly increased risk (hazard $1.39,1.12$ to 1.73 ) but no dose-response emerged

(supplementary table B). The association with exposure before age 20 was similar $(1.37,1.11$ to 1.68$)$, with some indication of a dose-response. There was no evidence of an increased risk of breast cancer associated with exposure at ages 30-39. The unweighted excess relative risks per Gy for exposures before ages 40 and 30 were $3.90(\mathrm{P}=0.121)$ and $5.54(\mathrm{P}=0.107)$. In the analysis of specific diagnostic procedures we found no significant associations between specific procedures and risk of breast cancer (supplementary table C). Based on only a few cases, exposure to computed tomography before age 30 seemed to be associated with increased risk of breast cancer $(2.36,0.71$ to 7.88 ).

\section{Discussion \\ Principal findings}

In this large European study, exposure to diagnostic radiation before age 30 was associated with an increased risk of breast cancer in BRCA1/2 mutations, at dose levels considerably lower than those at which increases have been found in other cohorts exposed to radiation. We estimated the cumulative breast dose from various exposures to diagnostic radiation and observed increases in risk for exposure before age 30 , even for a relatively low dose category (that is, below 0.0066 Gy0. No association with risk of breast cancer was apparent for exposure at ages 30-39.

\section{Comparison with other studies}

Two previous studies among women with BRCA1/2 mutations who had undergone mammography observed no association with risk of breast cancer. ${ }^{9}{ }^{10}$ This could be because of the relatively high age at first mammogram, which was on average 35 , while in our study it was 29.5 (SD 5.8) years. We observed a 1.4-fold increased risk of breast cancer after mammography before age 30 with a (non-significant) pattern of dose-response (table 5). We were concerned that this latter association might be attributed to confounding by indication - that is, self selection for early mammography in carriers with a strong family history of breast cancer. This was not the case as the association between cumulative breast dose and risk of breast cancer remained after we excluded carriers who had had mammography (table 6). Confounding by indication on the other diagnostic procedures is highly unlikely.

Two other studies have reported an association between self reported exposure to chest radiography and risk of breast cancer in BRCA carriers. ${ }^{78}$ Risks were particularly high among those exposed before age 20 . Some of our participants $(21 \%)$ were also included in one of these previous studies, the IBCCS. ${ }^{7}$ In their subcohort, the IBCCS reported a 1.8-fold increased risk while we observed a 1.4-fold non-significantly increased risk (hazard ratio $1.38,95 \%$ confidence interval 0.87 to 2.20 ; data not shown) for exposure to radiography. This difference could be explained by the fact that we excluded radiographs received after age 40 and less than five years before diagnosis while the IBCCS had included all lifetime radiographs, including those after diagnosis of breast cancer. Exclusion of the overlapping group did not materially affect our results.

We hypothesised that BRCA carriers could have increased radiosensitivity because of impaired DNA repair mechanisms. We observed increased risks of breast cancer among BRCA1/2 mutation carriers at dose levels considerably lower than those at which increases have been found in other cohorts exposed to radiation. A pooled analysis of eight cohorts exposed to radiation estimated a relative risk of about 2.0 at a dose of $1 \mathrm{~Gy}$, assuming an age at exposure of 25 years. ${ }^{17}$ Nowadays, the dose estimate to the breast from a two view mammogram is in the order of 4 mGy. Even in women who reported undergoing a large number of mammograms, the total radiation dose to the breast is unlikely to exceed $20 \mathrm{mGy}$. This corresponds to a predicted relative risk of less than 1.02 based on the Preston model, which is substantially less than the risk estimates we observed.

In the general population, a minimal induction time for breast cancer of 10 to 15 years after exposure to radiation is generally accepted, with relative risks decreasing as a function of attained age after reaching a peak, usually between the age of 30 and $40 .{ }^{17}{ }^{18}$ As we hypothesised that BRCA carriers could have increased radiosensitivity because of impaired DNA repair mechanisms, we used a five year time lag in our analyses. Analyses with a two or 10 year time lag showed similar results (data not shown). Analyses stratified by attained age $(\leq 40 v$ $>40$ ) showed no significant effect modification. In line with published literature ${ }^{19}$ we observed a slightly stronger risk for the younger attained age group. It is possible that we did not see a strong effect of attained age because of limited variation in attained age in our study population. Alternatively, it could be that the attained age/time since exposure effect in BRCA1/2 carriers differs from that in the general population.

\section{Strengths and limitations}

Several strengths and weaknesses of our study should be considered in the interpretation of these results. The strengths 
of our study include the sample size and the detailed information on all diagnostic procedures that used ionising radiation in different age periods. While previous studies ${ }^{78} 9^{10}$ were based only on mammography or radiography, we also investigated types of diagnostic exposures other than mammography and radiography in carriers and calculated one estimate of total radiation dose. The weighted cohort approach was used to overcome testing bias. The changes of the hazard ratios from the weighting (see supplementary tables $\mathrm{C}$ and D) were relatively small and in the expected direction, so the weights seem to meet their purpose of taking away some testing bias. The weighting procedure does not have any impact on the interpretation of the results. The retrospective nature of our study, however, might have caused recall bias. We relied on self reports rather than review of medical records because of the difficulties in accessing medical records with regard to the various diagnostic procedures. These took place for many different indications and many occurred in the distant past. Two methodological studies in the Dutch cohort (test-retest reliability ${ }^{20}$ and validity ${ }^{21}$ of self reported diagnostic radiation) showed that the extent of the observed misclassification was small and mainly non-differential by disease status, consistent with other studies. ${ }^{22-25}$ In the validation study, for example, the proportion agreement and $\kappa$ for ever/never having had a mammogram before age 30 was $>90 \%$ and $>0.80$, respectively, and this was not different between cases and unaffected carriers $(\mathrm{P}=0.237) .{ }^{21}$ Therefore, recall bias seems unlikely in our study and the observed non-differential misclassification might have biased our results towards unity. Non-differential

misclassification could also have occurred because exposure before age 10 is unlikely to have been recalled by women. Also, exposure before age 20 is more difficult to recall than exposure at higher and thus more recent ages. Therefore, in our study, exposure before age 20 could have been prone to more non-differential misclassification than exposure at ages 20-29. This might explain the similar relative risks observed for both age groups, in contrast with what was observed in radiation exposed cohorts that did not rely on self reports. ${ }^{17}$ Furthermore, our follow-up might not have been long enough to detect an association between radiation exposure at ages 30-40 and risk of breast cancer.

The calculation of the cumulative dose estimate was based on several assumptions. Firstly, we did not use indication specific dose estimates for fluoroscopy and radiography. Most (>95\%) fluoroscopies before age 20, however, were chest fluoroscopies for tuberculosis screening and originated from the Dutch cohort (where mass population screening for tuberculosis in young people was performed $\left.1940-60^{26}\right)$. For radiography before age 20 , most ( $>90 \%$ ) were chest radiographs for which the dose $(0.0005 \mathrm{~Gy})$ differed from the dose of shoulder radiography for exposures before 1974 only (0.0010 Gy). ${ }^{27}$ Secondly, we dealt with missing values by single stratified mean imputation or by including a separate category. We think that this did not influence our results because the proportion of missing values was not different for cases and unaffected carriers. Moreover, missing values were imputed only if the exposure was known to have occurred in the relevant age period. Thirdly, we assumed that differences in dose estimates between the three European countries would be small as the recent country specific dose estimates for mammography for the UK and the Netherlands were similar. Nevertheless, for all types of diagnostic procedures, large differences might exist between machines and hospitals. Fourthly, the dose estimates for mammography were based on a two view mammogram. The doses used are typical doses for an average woman, but there are large variations depending on several characteristics of patients (such as breast size) and parameters of the equipment. Finally, we assumed the breast dose estimate reflected breast dose, assuming that the estimates reflect absorbed dose to fibroglandular tissue. This might apply only to mammography because those estimates were derived from entrance surface dose to dose to fibroglandular tissue. But we doubt that this is the case for the other diagnostic procedures.

The assumptions regarding cumulative dose estimate and the previously discussed non-differential misclassification, together with the small number of cases in some analyses, could have contributed to a lack of consistent dose-response trends. We consider that it is unlikely that there is no true effect because the overall pattern indicates increased risks; hazard ratios are already increased, albeit non-significantly for the lowest dose category, and remain increased for all categories of higher dose.

The stronger associations observed in the subcohort compared with the entire cohort are intriguing and suggest survival bias in the entire cohort. Although little is known about the influence of exposure to ionising radiation at low or high doses on overall survival and breast cancer specific survival in carriers, one study showed that radiation associated breast cancer had a distinct, less favourable, gene expression profile. ${ }^{15}$ Another explanation for the differences between the two analytical cohorts could be more non-differential misclassification in the entire cohort, in which the mean age at questionnaire completion was higher than in the subcohort (50.7 (SD 8.8) and 41.1 (9.7) years, respectively, $\mathrm{P}<0.001)$. Older age at questionnaire completion was a significant predictor of the proportion of disagreement in the test-retest reliability study. ${ }^{20}$ Although based on a smaller number, we consider the results from the subcohort to be the most valid because they are unlikely to be affected by survival bias. A prospective analysis was not possible because the number of incident cases was too small $(n=11)$. Incident case numbers in our study and others studies are not expected to increase rapidly because of the increasing uptake of prophylactic surgery in unaffected carriers and the relatively short follow-up since DNA testing became available (1995), together with the fact that many newly identified carriers were tested because they (already) had breast cancer.

\section{Unanswered questions and future research}

The linear non-threshold model is widely accepted to also apply to estimation of risk after low doses and is used in radiation protection. ${ }^{28}{ }^{29}$ Linear non-threshold extrapolation, however, might not apply to groups with a genetic susceptibility for increased radiosensitivity. Also, a few studies seem to show some differences in the biological responses to high and low dose radiation..$^{30}$ Our data are inconsistent with a threshold. The category specific hazard ratios (1.00 (reference), 1.6, 1.8, 1.8, and 3.8 for dose categories $<0.002,0.002-0.0065$,

0.0066-0.0173, and $\geq 0.0174 \mathrm{~Gy}$, see table 4 , exposure before age 30) are already increased, albeit non-significantly, for the lowest dose category and remain increased for all categories of higher dose. When we evaluated curvature by adding quadratic dose to a model with continuous dose, there was some evidence for concavity - that is, downward curvature $(\mathrm{P}=0.009$ for quadratic term). Because there are relatively few cases in the high dose range, this result must be interpreted with caution. The possibility of a dose-response relation other than linear warrants further investigation.

To indicate the clinical relevance of our results we calculated the absolute risk of breast cancer for exposure before age 30 . Nowadays, the glandular dose of a single two view mammogram 
is around $4 \mathrm{mGy}$. This falls into the second dose category (0.0020-0.0065). According to our study results, the hazard of breast cancer associated with a mammogram taken between age 20 and 29 was 1.55 (95\% confidence interval 0.76 to 3.17 ; see table 4). For a 30 year old carrier, the risk of developing breast cancer at age 40 (mean age at diagnosis in our study) is about $9 \%$ (assuming a 2:1 ratio of BRCA1 and BRCA2). ${ }^{31}$ This means that among 100 carriers aged 30, nine will have developed breast cancer by age 40 . The absolute number of cases would increase by five $((1.55 \times 9)-9)$ if all had had one mammogram before age 30 . Because of the previously described study limitations and because currently there are no definitive international baseline mutation specific estimates of penetrance for risk of breast cancer among BRCA1/2 mutation carriers, however, this estimate should be interpreted with caution.

An interesting finding is the difference we observed in the association between exposure to diagnostic radiation and risk of breast cancer for BRCA1 and BRCA2 carriers. For age specific exposure effects, however, the power in the BRCA2 group was rather low. Future studies should focus on prospective follow-up and examine modifying effects by genotype in larger populations, for exposure to both low and high dose ionising radiation.

\section{Conclusions and policy implications}

In conclusion, in this large European study among BRCA1/2 mutation carriers, exposure to diagnostic radiation before age 30 was associated with an increased risk of breast cancer, at dose levels considerably lower than those at which increases have been found in other cohorts exposed to radiation. The results of this study support the recommendation to use non-ionising radiation imaging techniques (such as MRI) as the main tool for surveillance in young BRCA1/2 mutation carriers.

We thank Vanessa Tenet, Claude Picard, Irwin Piot, Esther Janssen, Monica Legdeur, Josette van As, and Renée Mulder for their help in data collection, entry, and cleaning; D Richardson and M Schaapveld for their help with the analysis of excess relative risks; M Bleiker and S Muller for their advice on dosimetry issues; Lesley Richardon for assistance in the design and conduct of the Gene-Rad-Risk study; and Dillwyn Williams for his support and advice on the EMBRACE radiation history study.

Centres and individuals of the three nationwide studies GENEPSO (Gene Etude Prospective Sein Ovaire, France) Coordinating Centre, Centre René Hugenin, Saint Cloud: Catherine Noguès, Emmanuelle Fourme, Rosette Lidereau, Denise Stevens; Institut Curie, Paris: Dominique Stoppa-Lyonnet, Marion Gauthier-Villars; Institut Gustave Roussy, Villejuif: Agnès Chompret; Centre René Huguenin, Saint Cloud: Catherine Noguès; Centre Paul Strauss, Strasbourg: Jean-Pierre Fricker; Centre François Baclesse, Caen: Pascaline Berthet; Centre Alexis Vautrin, Vandoeuvre-les-Nancy: Elisabeth Luporsi; Centre Léon Bérard, Lyon: Christine Lasset, Valérie Bonadona; Centres Paul Papin, René Gauducheau, and Catherine de Sienne, Angers, Nantes: Alain Lortholary; Centre Antoine Lacassagne, Nice: Marc Frénay; Hôpital D’Enfants Centre Hospitalier Universitaire, Dijon: Laurence Faivre; Institut Paoli-Calmettes, Marseille: Hagay Sobol, François Eisinger, Laetitia Huiart; Institut Bergonié, Bordeaux: Michel Longy; Institut Jean Godinot, Reims: Tan Dat Nguyen; Institut Claudius Regaud, Toulouse: Laurence Gladieff, Rosine Guimbaud; Centre Hospitalier Georges Renon, Niort: Paul Gesta; Centre Oscar Lambret, Lille: Philippe Vennin, Claude Adenis; Hôpital Charles Nicolle, Centre Henri Becquerel, Rouen: Annie Chevrier, Annick Rossi; Centre Jean Perrin, Clermont-Ferrand: Yves-Jean Bignon; Hôpital Civil, Strasbourg: Jean-Marc Limacher; Centre Eugène Marquis, Rennes: Catherine
Dugast; Polyclinique Courlancy, Reims: Liliane Demange; Hôpital de la Timone, Marseille: Hélène Zattara-Cannoni; Clinique Sainte Catherine, Avignon: Hélène Dreyfus; Centre Hospitalier Universitaire Arnaud Villeneuve, Montpellier: Mehrdad Noruzinia; and Centre Hospitalier Régional et Universitaire Dupuytren, Limoges: Laurence Venat-Bouvet. EMBRACE (Epidemiological Study of BRCA1 and BRCA2 mutation carriers, UK)

Coordinating Centre, Cambridge: Susan Peock, Margaret Cook, Debra Frost, Clare Oliver; North of Scotland Regional Genetics Service, Aberdeen: Helen Gregory; West Midlands Regional Clinical Genetics Service, Birmingham: Trevor Cole, Lucy Burgess; East Anglian Regional Genetics Service, Cambridge: Joan Paterson; Medical Genetics Services for Wales, Cardiff: Mark Rogers, Lisa Hughes; Peninsula Clinical Genetics Service, Exeter: Carole Brewer; West of Scotland Regional Genetics Service, Glasgow: Rosemarie Davidson, Nicola Bradshaw; South East Thames Regional Genetics Service, London: Louise Izatt, Gabriella Pichert, Caroline Langman; Yorkshire Regional Genetics Service, Leeds: Carol Chu, Julie Miller; Manchester Regional Genetics Service, Manchester: Gareth Evans, Fiona Lalloo, Andrew Shenton; Oxford Regional Genetics Service, Oxford: Lucy Side; Department of Cancer Genetics, Royal Marsden NHS Foundation Trust: Ros Eeles, Elizabeth Bancroft, Elizabeth Page, Elena Castro, Audray Ardern-Jones, Richard Houlston, Nazneen Rahman, Susan Shanley; North Trent Clinical Genetics Service, Sheffield: Jackie Cook, Lauren Baxter; South West Thames Regional Genetics Service, London: Shirley Hodgson, Sheila Goff; and Wessex Clinical Genetics Service, Southampton: Diana Eccles. Gareth Evans and Fiona Lalloo are supported by an NIHR grant to the Biomedical Research Centre, Manchester. The investigators at The Institute of Cancer Research and The Royal Marsden NHS Foundation Trust are supported by an NIHR grant to the Biomedical Research Centre at The Institute of Cancer Research and The Royal Marsden NHS Foundation Trust. Ros Eeles and Elizabeth Bancroft are also supported by Cancer Research UK Grant C5047/A8385.

HEBON (Netherlands Collaborative Group on Hereditary Breast Cancer, Netherlands)

Coordinating center: Netherlands Cancer Institute, Amsterdam: Senno Verhoef, Anouk Pijpe, Richard Brohet, Frans Hogervorst, Laura van 't Veer, Flora van Leeuwen, Matti Rookus; Erasmus Medical Center, Rotterdam: Margriet Collée, Ans van den Ouweland, Mieke Kriege, Mieke Schutte, Maartje Hooning, Caroline Seynaeve; Leiden University Medical Center, Leiden: Rob Tollenaar, Christi van Asperen, Juul Wijnen, Peter Devilee; Radboud University Nijmegen Medical Centre, Nijmegen: Nicoline Hoogerbrugge, Marjolijn Ligtenberg; University Medical Center Utrecht, Utrecht: Margreet Ausems, Rob van der Luijt; Amsterdam Medical Center: Cora Aalfs, Theo van Os; VU University Medical Center, Amsterdam: Hanne Meijers-Heijboer, Hans Gille; University Hospital Maastricht, Maastricht: Encarna Gomez-Garcia, Rien Blok; University Medical Center Groningen, Groningen: Jan Oosterwijk, Annemiek van der Hout; Netherlands Foundation for Detection of Hereditary Tumours, Leiden: Hans Vasen, Inge van Leeuwen.

Contributors: AP, NA, DFE, AK, EC, DG, FEvL, and MAR were responsible for study concept and design. AP, DFE, CN, MG-V, CL, J-PF, SP, DF, DGE, RAE, JP, PM, CJvA, MGEMA, HM-H, IT-C, and MAR acquired the data. AP, NA, DFE, AK, MH, FEvL, and MAR analysed and interpreted the data. AP, NA, DFE, AK, FEvL, and MR drafted the manuscript, which was critically revised for important intellectual content by all authors. AP, NA, DFE, AK, MH, FEvL, and MR carried out the statistical analyses. NA, DFE, EC, CN, MAR, and FEvL obtained funding. AP, NA, DFE, AK, EC, CN, SP, PM, MAR, and FEvL supervised the study. All authors commented on and approved the final draft. FEvL is guarantor.

Funding: The GENE-RAD-RISK study was supported by grant No 012926 (FI6R) under Euratom Programme; GENEPSO: Fondation de France and Ligue National Contre le Cancer; EMBRACE: Cancer Research UK (grant C1287/A10118 and C1287/A8874); HEBON: Dutch 


\section{What is already known on this topic}

Epidemiological studies on the association between diagnostic radiation and risk of breast cancer in BRCA1/2 mutation carriers have inconclusive results, possibly because of limitations such as the investigation of a single type of diagnostic procedure, relatively small numbers and lack of dose estimates, and a retrospective design with potential recall and survival bias

\section{What this study adds}

In BRCA1/2 mutation carriers, exposure to diagnostic radiation before the age of 30 was associated with an increased risk of breast cancer, at dose levels considerably lower than those at which increases have been found in other cohorts exposed to radiation While previous studies were based only on mammography or radiography, this large cohort study used estimates of an individual age specific cumulative breast dose from various diagnostic radiation procedures as a measure of total diagnostic radiation exposure The results support the use of non-ionising radiation imaging techniques (such as MRI) for surveillance in young with BRCA1/2 mutations

Cancer Society (grants NKI1998-1854, NKI2004-3088, NKI 2007-3756). DFE is a principal research fellow of Cancer Research UK. The sponsors had no role in the design of the study; in the collection, analysis, and interpretation of the data; in the writing of the report; and in the decision to submit the paper for publication.

Competing interests: All authors have completed the ICMJE uniform disclosure form at www.icmje.org/coi_disclosure.pdf (available on request from the corresponding author) and declare: DFE is board member of Genome Canada. RAE receives royalties for the book Genetic Predisposition to Cancer, has received educational grants from Tepnel, Illumina, and Vista Diagnostics and has received honoraria for BRCA-related lectures from MD Anderson and University of Southampton. DG receives royalties from BRCA1 testing. Ethical approval: The study was approved by the medical ethics committees of all participating centres (Commission nationale de l'informatique et des libertés, France; Cambridgeshire 4 Research Ethics Committee; Netherlands Cancer Institute-Antoni van Leeuwenhoek Hospital, Amsterdam), and all participants provided written informed consent.

Data sharing: No additional data available.

1 Ronckers CM, Erdmann CA, Land CE. Radiation and breast cancer: a review of current evidence. Breast Cancer Res 2005;7:21-32.

2 Powell SN, Kachnic LA. Roles of BRCA1 and BRCA2 in homologous recombination, DNA replication fidelity and the cellular response to ionizing radiation. Oncogene 2003;22:5784-91

3 Venkitaraman AR. Cancer susceptibility and the functions of BRCA1 and BRCA2. Cell 2002;108:171-82.

4 Yoshida K, Miki Y. Role of BRCA1 and BRCA2 as regulators of DNA repair, transcription, and cell cycle in response to DNA damage. Cancer Sci 2004:95:866-71.

5 Nieuwenhuis B, Van Assen-Bolt AJ, Van Waarde-Verhagen MA, Sijmons RH, Van der Hout AH, Bauch T, et al. BRCA1 and BRCA2 heterozygosity and repair of X-ray-induced DNA damage. Int J Radiat Biol 2002;78:285-95.

6 Boulton SJ. Cellular functions of the BRCA tumour-suppressor proteins. Biochem Soc Trans 2006;34:633-45.

7 Andrieu N, Easton DF, Chang-Claude J, Rookus MA, Brohey MR, Cardis E, et al. Effect of chest X-rays on the risk of breast cancer among BRCA1/2 mutation carriers in the international BRCA1/2 carrier cohort study: a report from the EMBRACE, GENEPSO, GEO-HEBON, and IBCCS Collaborators' Group. J Clin Oncol 2006;24:3361-6.

8 Gronwald J, Pijpe A, Byrski T, Huzarski T, Stawicka M, Cybulski C, et al. Early radiation exposures and BRCA1-associated breast cancer in young women from Poland. Breast Cancer Res Treat 2008;112:581-4

9 Goldfrank D, Chuai S, Bernstein JL, Ramon Y, Cajal T, Lee JB, et al. Effect of mammography on breast cancer risk in women with mutations in BRCA1 or BRCA2. Cancer Epidemiol Biomarkers Prev 2006;15:2311-3.

10 Narod SA, Lubinski J, Ghadirian P, Lynch HT, Moller P, Foulkes WD, et al. Screening mammography and risk of breast cancer in BRCA1 and BRCA2 mutation carriers: a case-control study. Lancet Oncol 2006;7:402-6.

11 EMBRACE. http://ccge.medschl.cam.ac.uk/embrace.

12 Pijpe A, Manders P, Brohet RM, Collee JM, Verhoef S, Vasen HF, et al. Physical activity and the risk of breast cancer in BRCA1/2 mutation carriers. Breast Cancer Res Treat 2010;120:235-44

13 Antoniou AC, Goldgar DE, Andrieu N, Chang-Claude J, Brohet R, Rookus MA, et al. A weighted cohort approach for analysing factors modifying disease risks in carriers of high-risk susceptibility genes. Genet Epidemiol 2005;29:1-11.

14 Antoniou A, Pharoah PD, Narod S, Risch A, Eyfjord JE, Hopper JL, et al. Average risks of breast and ovarian cancer associated with BRCA1 or BRCA2 mutations detected in case Series unselected for family history: a combined analysis of 22 studies. Am J Hum Genet 2003;72:1117-30.

15 Broeks A, Braaf LM, Wessels LF, van de Vijver M, De Bruin ML, Stovall M, et al. Radiation-associated breast tumors display a distinct gene expression profile. Int $J$ Radiat Oncol Biol Phys 2010;76:540-7.
16 Langholz B, Richardson DB. Fitting general relative risk models for survival time and matched case-control analysis. Am J Epidemiol 2010;171:377-83.

17 Preston DL, Mattsson A, Holmberg E, Shore R, Hildreth NG, Boice JD Jr. Radiation effects on breast cancer risk: a pooled analysis of eight cohorts. Radiat Res 2002;158:220-35.

18 Land CE, Tokunaga M, Koyama K, Soda M, Preston DL, Nishimori I, et al. Incidence of female breast cancer among atomic bomb survivors, Hiroshima and Nagasaki, 1950-1990. Radiat Res 2003;160:707-17.

19 Land CE. Studies of cancer and radiation dose among atomic bomb survivors. The example of breast cancer. JAMA 1995;274:402-7.

20 Pijpe A, Manders P, Mulder RL, van Leeuwen FE, Rookus MA. Reliability of self-reported diagnostic radiation history in BRCA1/2 mutation carriers. Eur J Epidemiol 2010;25:103-13.

21 Pijpe A, Mulder RL, Manders P, van Leeuwen FE, Rookus MA. Validation study suggested no differential misclassification of self-reported mammography history in BRCA1/2 mutation carriers. J Clin Epidemiol 2011;64:1434-43.

22 Norman SA, Localio AR, Zhou L, Berstein L, Coates RJ, Flagg EW, et al. Validation of self-reported screening mammography histories among women with and without breast cancer. Am J Epidemiol 2003;158:264-71.

23 Pogoda JM, Preston-Martin S. Radiation exposure from diagnostic imaging: agreement between self-report and medical records. Health Phys 2002;83:907-17.

24 Berrington de Gonzalez A, Ekbom A, Glass AG, Galanti MR, Grimelius L, et al. Comparison of documented and recalled histories of exposure to diagnostic $x$-rays in case-control studies of thyroid cancer. Am J Epidemiol 2003;157:652-63.

25 Preston-Martin S, Bernstein L, Maldonado AA, Henderson BE, White SC. A dental x-ray validation study. Comparison of information from patient interviews and dental charts. $A m$ $J$ Epidemiol 1985;121:430-9.

26 Sickenga FN. Short history of the tuberculosis suppression in the Netherlands 1900-1960 [in Dutch]. KNCV Tuberculosisfoundation, 1980.

27 Sigurdson AJ, Bhatti P, Doody MM, Hauptmann M, Bowen L, Simon SL, et al. Polymorphisms in apoptosis- and proliferation-related genes, ionizing radiation exposure, and risk of breast cancer among US Radiologic Technologists. Cancer Epidemiol Biomarkers Prev 2007;16:2000-7.

28 International Commission of radiological protection (ICRP). Recommendations of the ICRP. Elsevier, 2007 (publication 103).

29 National Research Council. Health risks from exposure to low levels of ionizing radiation (BEIR VII). National Academy Press, 1999.

30 Mullenders L, Atkinson M, Paretzke H, Sabatier L, Bouffler S. Assessing cancer risks of low-dose radiation. Nat Rev Cancer 2009;9:596-604.

31 Chen S, Parmigiani G. Meta-analysis of BRCA1 and BRCA2 penetrance. J Clin Oncol 2007;25:1329-33.

32 Sickenga FN. Observations on radiation hazards, with special reference to roentgen examinations of tuberculosis [in Dutch]. Ned Tijdschr Geneeskd 1959;103:1998-2005.

33 Drion R, Kiestra S, Peters A. Radiation dosage in fluoroscopy at a consultation office for tuberculosis control [in Dutch]. Ned Tijdschr Geneeskd 1961;105:1920-3.

34 Sickenga FN. Radiation dosage in fluoroscopy [in Dutch]. Ned Tijdschr Geneeskd 1961;105:2417-9.

35 Howe GR, McLaughlin J. Breast cancer mortality between 1950 and 1987 after exposure to fractionated moderate-dose-rate ionizing radiation in the Canadian fluoroscopy cohort study and a comparison with breast cancer mortality in the atomic bomb survivors study. Radiat Res 1996;145:694-707.

36 Land CE. Low-dose radiation-a cause of breast cancer? Cancer 1980;46(4 suppl):868-73.

37 Eleveld $\mathrm{H}$. Ionising radiation exposure in the Netherlands, RIVM report 861020002. 2003. www.rivm.nl/ims.

38 Meeuwsen EJ. Informatiesysteem Medische Stralingstoepassingen 2006, RIVM report 300081001 [in Dutch]. 2007. www.rivm.nl/ims.

39 Young KC, Burch A. Radiation doses received in the UK Breast Screening Programme in 1997 and 1998. Br J Radiol 2000;73:278-87.

40 Young KC, Burch A, Oduko JM. Radiation doses received in the UK Breast Screening Programme in 2001 and 2002. Br J Radiol 2005;78:207-18.

Accepted: 10 August 2012

\section{Cite this as: BMJ 2012;345:e5660}

This is an open-access article distributed under the terms of the Creative Commons Attribution Non-commercial License, which permits use, distribution, and reproduction in any medium, provided the original work is properly cited, the use is non commercial and is otherwise in compliance with the license. See: http://creativecommons.org/licenses/by$\mathrm{nc} / 2.0 /$ and http://creativecommons.org/licenses/by-nc/2.0/legalcode. 


\section{Tables}

Table 1/ Estimated doses of radiation (in Gy) to breast of diagnostic radiographic procedures by time period

\begin{tabular}{|c|c|c|c|c|}
\hline & Fluoroscopy ${ }^{*}$ & Radiography† & Mammographył & Computed tomography† \\
\hline $1930-39$ & 0.0100 & NA & NA & NA \\
\hline $1940-59$ & 0.0100 & 0.0005 & NA & NA \\
\hline $1960-64$ & 0.0050 & 0.0005 & 0.0158 & NA \\
\hline $1965-69$ & 0.0050 & 0.0005 & 0.0186 & NA \\
\hline$\underline{1970-74}$ & 0.0050 & 0.0005 & 0.0126 & NA \\
\hline $1975-79$ & 0.0050 & 0.0005 & 0.0090 & 0.0200 \\
\hline $1980-84$ & 0.0050 & 0.0005 & 0.0066 & 0.0200 \\
\hline $1985-89$ & 0.0050 & 0.0005 & 0.0042 & 0.0200 \\
\hline $1990-94$ & 0.0050 & 0.0005 & $0.0042(\mathrm{NL}) ; 0.0036(\mathrm{UK}) ; 0.0039(\mathrm{FR})$ & 0.0200 \\
\hline $1995-99$ & 0.0050 & 0.0005 & $0.0042(\mathrm{NL}) ; 0.0041(\mathrm{UK}) ; 0.0042$ (FR) & 0.0200 \\
\hline $2000-04$ & 0.0050 & 0.0005 & $0.0035(\mathrm{NL}) ; 0.0043(\mathrm{UK}) ; 0.0039(\mathrm{FR})$ & 0.0200 \\
\hline 2005-07 & 0.0050 & 0.0005 & $0.0035(\mathrm{NL}) ; 0.0043(\mathrm{UK}) ; 0.0039(\mathrm{FR})$ & 0.0200 \\
\hline
\end{tabular}

$\mathrm{NA}=$ not applicable (procedure did not exist or nobody exposed); NL=Netherlands; FR=France.

${ }^{*}$ Based on published data ${ }^{2632-36}$ and expert judgment of IT-C, AK, FvL, and AP (June 2009)

†Based on Sigurdson et al. ${ }^{27}$

‡Doses estimated by IT-C and AK (September 2009) for 1960-89; and taken from published sources for $1990-2007$ (NL, ${ }^{3738}$ UK, ${ }^{39} 40$ and FR (average of dose NL and UK). 
Table 2| Characteristics of entire cohort ( $n=1993)$ of BRCA1/2 mutation carriers and subcohort $(n=1122)$ of relatively recent cases. Figures are numbers* (percentage) of participants

\begin{tabular}{|c|c|c|c|c|}
\hline \multirow[b]{2}{*}{ Characteristic } & \multicolumn{2}{|c|}{ Entire cohort } & \multicolumn{2}{|c|}{ Subcohort $†$} \\
\hline & Cohort $(n=1993)$ & Cases $(n=848 \ddagger)$ & Cohort $(n=1122)$ & Cases $(n=174)$ \\
\hline \multicolumn{5}{|l|}{ Gene: } \\
\hline BRCA1 & $1290(65)$ & $575(68)$ & $685(61)$ & $114(66)$ \\
\hline BRCA2 & $703(35)$ & $279(32)$ & $437(39)$ & $60(34)$ \\
\hline \multicolumn{5}{|l|}{ Birth cohort: } \\
\hline$<1955$ & $462(23)$ & $281(33)$ & $127(11)$ & $22(13)$ \\
\hline $1955-61$ & $517(26)$ & $291(34)$ & $224(20)$ & $48(27)$ \\
\hline $1962-68$ & $508(26)$ & $213(25)$ & $315(28)$ & $70(40)$ \\
\hline$>1968$ & $506(25)$ & $63(7)$ & $456(40)$ & $34(20)$ \\
\hline \multicolumn{5}{|l|}{ Study (country): } \\
\hline GENEPSO (France) & $716(35)$ & $257(30)$ & $477(43)$ & $37(21)$ \\
\hline EMBRACE (UK) & $688(35)$ & $339(40)$ & $408(36)$ & $107(62)$ \\
\hline HEBON (Netherlands) & $589(30)$ & $252(30)$ & $237(21)$ & $30(17)$ \\
\hline \multicolumn{5}{|l|}{ Age at menarche (years): } \\
\hline$\leq 12$ & $725(37)$ & $311(37)$ & $398(36)$ & $57(33)$ \\
\hline 13 & $595(30)$ & $247(29)$ & $355(32)$ & $59(34)$ \\
\hline$\geq 14$ & $659(33)$ & $286(34)$ & $360(32)$ & $58(33)$ \\
\hline \multicolumn{5}{|l|}{ Parity: } \\
\hline Nulliparous & $476(24)$ & $152(18)$ & $316(27)$ & $34(20)$ \\
\hline Parous & $1515(76)$ & $695(82)$ & $805(73)$ & $140(80)$ \\
\hline \multicolumn{5}{|l|}{ No of children: } \\
\hline $1-2$ & $1111(73)$ & $519(75)$ & $589(73)$ & $104(74)$ \\
\hline$>2$ & $404(27)$ & $176(25)$ & $216(27)$ & $36(26)$ \\
\hline \multicolumn{5}{|l|}{ Age at first birth (years): } \\
\hline$<24$ & $482(32)$ & $248(35)$ & $225(28)$ & $41(29)$ \\
\hline $24-27$ & 497 (33) & $224(32)$ & $264(33)$ & $46(33)$ \\
\hline$\geq 28$ & $534(35)$ & $223(32)$ & $314(39)$ & $53(38)$ \\
\hline \multicolumn{5}{|l|}{ Breast feeding: } \\
\hline Never & $441(29)$ & $202(29)$ & $230(29)$ & $34(25)$ \\
\hline Ever & $1061(71)$ & $487(71)$ & $567(71)$ & $104(75)$ \\
\hline \multicolumn{5}{|l|}{ Menopausal status: } \\
\hline Premenopausal & $1573(79)$ & $747(88)$ & $791(71)$ & $130(75)$ \\
\hline Postmenopausal & $417(21)$ & $100(12)$ & $329(29)$ & $44(25)$ \\
\hline \multicolumn{5}{|l|}{ Type: } \\
\hline Natural & $151(36)$ & $56(56)$ & $90(27)$ & $14(32)$ \\
\hline Surgical, prophylactic & $266(64)$ & $44(44)$ & $239(73)$ & $30(68)$ \\
\hline
\end{tabular}

*Numbers do not always add up to $100 \%$ because of missing values.

†Subcohort includes carriers with diagnosis of breast cancer or censored within five years before questionnaire completion, with follow-up being counted only during this five year period.

łlncludes 11 incident cases that occurred after questionnaire completion; $5 \%$ of breast cancer diagnoses were ductal carcinomas in situ; for $7 \%$ type was unknown. 


\begin{tabular}{|c|c|c|c|c|}
\hline \multirow[b]{2}{*}{ Characteristic } & \multicolumn{2}{|c|}{ Entire cohort } & \multicolumn{2}{|c|}{ Subcohort† } \\
\hline & Cohort $(n=1993)$ & Cases $(n=848 \ddagger)$ & Cohort $(n=1122)$ & Cases $(n=174)$ \\
\hline \multicolumn{5}{|l|}{ Fluoroscopy: } \\
\hline Never & $1512(84)$ & $601(80)$ & $900(90)$ & $134(86)$ \\
\hline Ever & $280(16)$ & $153(20)$ & $100(10)$ & $21(14)$ \\
\hline Missing & 201 & 94 & 112 & 19 \\
\hline \multicolumn{5}{|l|}{ Radiography: } \\
\hline Never & $976(52)$ & $392(49)$ & $557(52)$ & $79(49)$ \\
\hline Ever & $919(48)$ & $403(51)$ & $521(48)$ & $83(51)$ \\
\hline Missing & 98 & 53 & 44 & 12 \\
\hline \multicolumn{5}{|l|}{ Mammography: } \\
\hline Never & $1312(67)$ & $624(74)$ & $643(58)$ & $100(58)$ \\
\hline Ever & $649(33)$ & $214(26)$ & $461(42)$ & $73(42)$ \\
\hline Missing & 32 & 10 & 18 & 1 \\
\hline \multicolumn{5}{|c|}{ Computed tomography: } \\
\hline Never & $1879(98)$ & $789(99)$ & $1063(98)$ & $164(98)$ \\
\hline Ever & $29(2)$ & $10(1)$ & $21(2)$ & $3(2)$ \\
\hline Missing & 85 & 49 & 38 & 7 \\
\hline \multicolumn{5}{|l|}{ Other§: } \\
\hline Never & $1868(97)$ & 794 (98) & $1038(96)$ & $157(96)$ \\
\hline Ever & $53(3)$ & $19(2)$ & $38(4)$ & $6(4)$ \\
\hline Missing & 72 & 35 & 46 & 11 \\
\hline \multicolumn{5}{|l|}{ Occupationalף: } \\
\hline Never & $1886(96)$ & $800(95)$ & $1056(95)$ & $159(92)$ \\
\hline Ever & $88(4)$ & $38(5)$ & $57(5)$ & $13(8)$ \\
\hline Missing & 19 & 10 & 9 & 2 \\
\hline \multicolumn{5}{|l|}{ Levelף: } \\
\hline Low & $44(50)$ & $15(39)$ & $31(54)$ & $4(31)$ \\
\hline Medium & $39(44)$ & $20(53)$ & $22(39)$ & $7(54)$ \\
\hline High & $5(6)$ & $3(8)$ & $4(7)$ & $2(15)$ \\
\hline \multicolumn{5}{|c|}{ Exposure during pregnancy/breastfeeding: } \\
\hline Never & $1871(96)$ & $795(96)$ & $1061(96)$ & $168(99)$ \\
\hline Ever & $81(4)$ & $33(4)$ & $41(4)$ & $1(1)$ \\
\hline Missing & 41 & 20 & 20 & 5 \\
\hline
\end{tabular}

*Numbers do not always add up to $100 \%$ because of missing values.

†Subcohort includes carriers with diagnosis of breast cancer or censored within five years before questionnaire completion, with follow-up being counted only during this five year period.

fIncludes 11 incident cases that occurred after questionnaire completion; $5 \%$ of breast cancer diagnoses were ductal carcinomas in situ; for $7 \%$ the type was unknown.

§Such as DXA and isotope thyroid.

IStudy questionnaire also covered occupational history. From this list, jobs with high likelihood of having had occupational radiation exposure, such as (dental) nurse, radiographers, stewardesses, were selected. Level of occupational exposure categorised as low, medium, or high based on combination of dose (low or high) and duration (short or long) of occupational exposure: low=low dose and short duration; medium=low dose and long duration or high dose and short duration; high=high dose and long duration. 
Table 4| Analyses of estimated cumulative breast dose of diagnostic radiation and risk of breast cancer for subcohort ( $n=1122)$ of BRCA1/2 mutation carriers

Subcohort ( $\mathrm{n}=1122 ; 174$ cases)*

\begin{tabular}{|c|c|c|c|}
\hline & & & \multirow{2}{*}{ Weighted hazard ratio $(95 \% \mathrm{Cl}) \dagger$} \\
\hline Exposure & Person years & Cases & \\
\hline \multicolumn{4}{|l|}{ Before age 20} \\
\hline Never & 2576 & 91 & 1.00 \\
\hline Ever & 1211 & 49 & 1.62 (1.02 to 2.58$)$ \\
\hline \multicolumn{4}{|l|}{ Dose category: } \\
\hline$<0.0020$ Gy & 748 & 31 & 1.47 (0.89 to 2.42$)$ \\
\hline $0.0020-0.0065$ Gy & 226 & 6 & 1.09 (0.41 to 2.91$)$ \\
\hline$\geq 0.0066$ Gy & $236 \ddagger$ & $12 \dagger$ & $3.16(1.19$ to 8.36$) \ddagger$ \\
\hline \multicolumn{4}{|l|}{ Aged 20-29 } \\
\hline Never & 2240 & 83 & 1.00 \\
\hline Ever & 1567 & 57 & 1.43 (0.93 to 2.21$)$ \\
\hline \multicolumn{4}{|l|}{ Dose category: } \\
\hline$<0.0020$ Gy & 690 & 21 & 1.13 (0.62 to 2.08$)$ \\
\hline $0.0020-0.0065$ Gy & 466 & 19 & 1.55 (0.76 to 3.17$)$ \\
\hline $0.0066-0.0173 \mathrm{~Gy}$ & 253 & 9 & 1.62 (0.68 to 3.83 ) \\
\hline$\geq 0.0174$ Gy & 157 & 8 & 2.11 (0.78 to 5.70$)$ \\
\hline \multicolumn{4}{|l|}{ Before age $30 \S$} \\
\hline Never & 1679 & 57 & 1.00 \\
\hline Ever & 2108 & 83 & $1.90(1.20$ to 3.00$)$ \\
\hline \multicolumn{4}{|l|}{ Dose category: } \\
\hline$<0.0020$ Gy & 874 & 33 & $1.63(0.96$ to 2.77$)$ \\
\hline $0.0020-0.0065$ Gy & 574 & 22 & 1.78 (0.88 to 3.58$)$ \\
\hline $0.0066-0.0173$ Gy & 413 & 14 & 1.75 (0.72 to 4.25$)$ \\
\hline$\geq 0.0174$ Gy & 245 & 14 & 3.84 (1.67 to 8.79 ) \\
\hline \multicolumn{4}{|l|}{ Aged 30-39 } \\
\hline Never & 2402 & 80 & 1.00 \\
\hline Ever & 1553 & 63 & 1.06 (0.66 to 1.71$)$ \\
\hline \multicolumn{4}{|l|}{ Dose category: } \\
\hline$<0.0020$ Gy & 194 & 8 & 0.88 (0.39 to 2.02 ) \\
\hline $0.0020-0.0065$ Gy & 492 & 22 & 1.29 (0.70 to 2.36$)$ \\
\hline 0.0066-0.0173 Gy & 539 & 20 & 0.83 (0.42 to 1.64$)$ \\
\hline$\geq 0.0174$ Gy & 327 & 13 & 1.30 (0.58 to 2.93$)$ \\
\hline \multicolumn{4}{|l|}{ Before age $40 \S$} \\
\hline Never & 1148 & 37 & 1.00 \\
\hline Ever & 2639 & 103 & 1.91 (1.12 to 3.26$)$ \\
\hline \multicolumn{4}{|l|}{ Dose category: } \\
\hline$<0.0020$ Gy & 615 & 23 & 1.59 (0.78 to 3.22$)$ \\
\hline $0.0020-0.0065$ Gy & 666 & 23 & 2.01 (1.02 to 3.95$)$ \\
\hline $0.0066-0.0173 \mathrm{~Gy}$ & 733 & 33 & 1.80 (0.91 to 3.54$)$ \\
\hline$\geq 0.0174 \mathrm{~Gy}$ & 624 & 24 & 2.31 (1.16 to 4.59 ) \\
\hline
\end{tabular}

Categorisation based on quartiles of cumulative dose at age 40 . Interquartile ranges by category: $<0.0020: 0.0005-0.0006 ; 0.0020-0.0065: 0.0035-0.0054$; 0.006-0.0173: 0.0092-0.0142; $\geq 0.0174: 0.0222-0.0435$.

*Subcohort includes carriers diagnosed with breast cancer or censored within five years before questionnaire completion, with follow-up being counted only during this five year period.

†Time varying Cox proportional hazards model, stratified for gene (BRCA1 and BRCA2), country, and birth cohort (<1955, 1955-61, 1962-68, >1968), clustered on family (930 clusters), and adjusted for age at entry in subcohort, parity (no children; 1-2 children; $>2$ children; time varying) and menopause (premenopausal; natural menopause; bilateral prophylactic oophorectomy; time varying); proportional hazards assumption for each covariate was evaluated by inspecting $\ln (-\ln ($ survival) $)$ curve, and using goodness of fit test; missing values coded as additional category. 
Table 4 (continued)

Subcohort ( $\mathrm{n}=1122 ; 174$ cases) ${ }^{*}$

¥For before age 20 , two upper categories $(0.0066-0.0174$ and $\geq 0.0174)$ were taken together.

§Before age 30 is sum of before age 20 and ages 20-29; before age 40 is sum of before age 20, ages 20-29, and ages 30-39. 
Table 5| Analyses on different types of diagnostic procedures by age period and risk of breast cancer for subcohort of 1122 BRCA1/2 mutation carriers

Subcohort $(n=1122 ; 174 \text { cases })^{\star}$

Person years

Cases

Weighted hazard ratio $(95 \% \mathrm{Cl}) \dagger$

Exposure before age 20

Fluoroscopy:

\begin{tabular}{|c|c|c|c|}
\hline Never & 3712 & 142 & 1.00 \\
\hline Ever & 320 & 13 & 1.30 (0.59 to 2.88$)$ \\
\hline \multicolumn{4}{|c|}{ No of fluoroscopies $¥:$} \\
\hline $1-2$ & 210 & 7 & 1.07 (0.38 to 3.00$)$ \\
\hline$>2$ & 110 & 6 & 2.01 (0.71 to 5.71$)$ \\
\hline \multicolumn{4}{|c|}{ Radiography: } \\
\hline Never & 3092 & 113 & 1.00 \\
\hline Ever & 1217 & 50 & 1.29 (0.84 to 1.98$)$ \\
\hline \multicolumn{4}{|c|}{ No of radiographs $\ddagger$ : } \\
\hline 1 & 568 & 24 & $1.30(0.79$ to 2.15$)$ \\
\hline 2 & 425 & 17 & 1.17 (0.59 to 2.30$)$ \\
\hline$>2$ & 223 & 9 & 1.43 (0.58 to 3.57$)$ \\
\hline \multicolumn{4}{|c|}{ Mammography: } \\
\hline Never & 436 & 171 & \multirow[t]{2}{*}{ NA§ } \\
\hline Ever & 7 & 3 & \\
\hline \multicolumn{4}{|c|}{ Exposure between age 20 and 29} \\
\hline \multicolumn{4}{|c|}{ Fluoroscopy: } \\
\hline Never & 3876 & 147 & 1.00 \\
\hline Ever & 172 & 8 & $1.72(0.74$ to 2.96$)$ \\
\hline \multicolumn{4}{|c|}{ No of fluoroscopies $\ddagger$ : } \\
\hline $1-2$ & 16 & 6 & \multirow[t]{2}{*}{ NA§ } \\
\hline$>2$ & 5 & 2 & \\
\hline \multicolumn{4}{|c|}{ Radiography: } \\
\hline Never & 3036 & 117 & 1.00 \\
\hline Ever & 1276 & 46 & $1.14(0.69$ to 1.86$)$ \\
\hline \multicolumn{4}{|c|}{ No of radiographs $\ddagger$ : } \\
\hline 1 & 570 & 22 & $0.98(0.54$ to 1.77$)$ \\
\hline $2-4$ & 572 & 15 & 1.14 (0.53 to 2.44$)$ \\
\hline$>4$ & 123 & 8 & $1.80(0.68$ to 4.71$)$ \\
\hline \multicolumn{4}{|c|}{ Mammography: } \\
\hline Never & 3,692 & 147 & 1.00 \\
\hline Ever & 709 & 27 & $1.31(0.76$ to 2.26$)$ \\
\hline \multicolumn{4}{|c|}{ No of mammogramsł: } \\
\hline 1 & 377 & 14 & $1.17(0.60$ to 2.30$)$ \\
\hline $2-4$ & 235 & 7 & $1.08(0.39$ to 3.00$)$ \\
\hline$>4$ & 96 & 6 & $2.35(0.64$ to 8.60$)$ \\
\hline \multicolumn{4}{|c|}{ Exposure before age 30} \\
\hline \multicolumn{4}{|c|}{ Fluoroscopy: } \\
\hline Never & 3622 & 136 & 1.00 \\
\hline Ever & 410 & 19 & 1.65 (0.89 to 3.08$)$ \\
\hline \multicolumn{4}{|c|}{ No of fluoroscopiesł: } \\
\hline $1-2$ & 245 & 12 & $1.66(0.77$ to 3.57$)$ \\
\hline$>2$ & 165 & 7 & $1.64(0.60$ to 4.50$)$ \\
\hline \multicolumn{4}{|c|}{ Radiography: } \\
\hline Never & 2451 & 90 & 1.00 \\
\hline
\end{tabular}


Table 5 (continued)

\begin{tabular}{|c|c|c|c|}
\hline & \multicolumn{3}{|c|}{ Subcohort ( $n=1122 ; 174$ cases) ${ }^{*}$} \\
\hline & Person years & Cases & Weighted hazard ratio $(95 \% \mathrm{Cl}) \dagger$ \\
\hline Ever & 1856 & 73 & $1.33(0.84$ to 2.08$)$ \\
\hline \multicolumn{4}{|c|}{ No of radiographs $\ddagger$ : } \\
\hline 1 & 636 & 28 & $1.40(0.81$ to 2.40$)$ \\
\hline 2 & 446 & 18 & 1.08 (0.56 to 2.08$)$ \\
\hline $3-4$ & 424 & 11 & $1.14(0.46$ to 2.81$)$ \\
\hline$>4$ & 349 & 16 & $1.83(0.84$ to 4.00$)$ \\
\hline \multicolumn{4}{|c|}{ Mammography: } \\
\hline Never & 3621 & 144 & 1.00 \\
\hline Ever & 775 & 30 & $1.43(0.85$ to 2.40$)$ \\
\hline \multicolumn{4}{|c|}{ No of mammogramsł: } \\
\hline 1 & 402 & 17 & 1.52 (0.83 to 2.79 ) \\
\hline $2-4$ & 277 & 7 & $0.87(0.30$ to 2.56$)$ \\
\hline$>4$ & 96 & 6 & $2.36(0.65$ to 8.60$)$ \\
\hline
\end{tabular}

*Subcohort includes carriers diagnosed with breast cancer or censored within five years before questionnaire completion, with follow-up being counted only during this five year period.

†Time-varying Cox proportional hazards model, stratified for gene (BRCA1 and BRCA2), country, and birth cohort (<1955, 1955-61, 1962-68, >1968), clustered on family (930 clusters) and adjusted for age at entry in the subcohort. For radiography and mammography, models were additionally adjusted for age at menarche $(\leq 12 ; 13 ; \geq 14)$, parity (no children; $1-2$ children; $>2$ children; time varying), and menopause (premenopausal; natural menopause; bilateral prophylactic oophorectomy; time varying). Proportional hazards assumption for each covariate evaluated by inspecting $\ln (-\ln ($ survival)) curve, and using goodness of fit test; missing values coded as additional category.

$\ddagger$ Depending on number of cases, categories for number of examinations might differ.

$\S$ Not available as power too low (<6 cases ever exposed or per category of number of exposures). 
Table $6 \mid$ Analyses of estimated cumulative breast dose of diagnostic radiation before age 30 and risk of breast cancer for BRCA $1 / 2$ mutation carriers who had never undergone mammography

\begin{tabular}{|c|c|c|c|}
\hline \multirow[b]{2}{*}{ Exposure } & \multicolumn{3}{|c|}{ Subcohort $(n=955 ; 144 \text { cases })^{*}$} \\
\hline & Person years & Cases & Unweighted hazard ratio $(95 \% \mathrm{Cl}) \dagger$ \\
\hline Never & 1679 & 57 & 1.00 \\
\hline Ever & 1412 & 58 & 1.65 (1.11 to 2.46$)$ \\
\hline \multicolumn{4}{|l|}{ Dose category: } \\
\hline$<0.0020$ Gy & 874 & 33 & $1.48(0.94$ to 2.33$)$ \\
\hline 0.0020-0.0065 Gy & 280 & 12 & 1.55 (0.81 to 2.98$)$ \\
\hline $0.0066-0.0173 \mathrm{~Gy}$ & 147 & 6 & $1.90(0.69$ to 5.21$)$ \\
\hline$\geq 0.0174$ Gy & 109 & 7 & 4.16 (2.01 to 8.62$)$ \\
\hline
\end{tabular}

* Subcohort includes carriers diagnosed or censored within five years before questionnaire completion, with follow-up being counted only during this five year period.

†Unweighted time varying Cox proportional hazards model, stratified for gene (BRCA1 and BRCA2), country, and birth cohort (<1955, 1955-61, 1962-68, >1968), clustered on family (816 clusters), and adjusted for age at entry in subcohort, parity (no children; 1-2 children; >2 children; time varying), and menopause (premenopausal; natural menopause; bilateral prophylactic oophorectomy; time varying); proportional hazards assumption for each covariate evaluated by inspecting In(-In(survival)) curve, and using goodness of fit test; missing values were coded as additional category. 